\title{
ARTIGO CIENTÍFICO
}

\section{Produção, aspectos nutricionais e fisiológicos de alface sob adubação foliar com Spirulina platensis}

\section{Production, mineral nutrition and physiological aspects of lettuce under foliar fertilization with Spirulina platensis}

\author{
Débora Samara Oliveira e Silva ${ }^{1}$, Jackson Silva Nóbrega ${ }^{2}$, Railene Hérica Carlos Rocha ${ }^{3}$, Josinaldo Lopes Araújo ${ }^{4}$, \\ Wellinghton Alves Guedes ${ }^{5 *}$, José Franciraldo de Lima ${ }^{6}$
}

\begin{abstract}
Resumo: Objetivou-se avaliar a influência de concentrações do fertilizante orgânico a base de Spirulina platensis sobre a produção, crescimento, teores de N, P, K e sódio e sobre as trocas gasosas de alface cv. Elba em condições de campo. Utilizouse o delineamento de blocos ao acaso, com seis tratamentos, constituídos das concentrações do fertilizante $(0 ; 1,5 ; 3,0 ; 4,5 ; 6,0$ e 7,5\%) com seis repetições. No ponto de colheita da cultura foram avaliadas variáveis de produção e crescimento, os teores de nitrogênio, fósforo, potássio e sódio, bem como, as trocas gasosas das plantas com o medidor de gás infravermelho (IRGA). Os resultados obtidos mostraram que as concentrações do fertilizante, não afetaram a produção, o crescimento, os teores de nutrientes avaliados, assim como não influenciaram as trocas gasosas das plantas.
\end{abstract}

Palavras-chave: Lactuca sativa; Microalga; Nutrição, Trocas gasosas.

Abstract: The objective of this study was to evaluate the influence of concentrations of organic fertilizer based on Spirulina platensis on yield, growth, in N, P, K and sodium contents and on gaseous changes of lettuce cv. Elba in field conditions. Use the design of randomized blocks, with six treatments consisting of different concentrations of fertilizer $(0 ; 1.5 ; 3.0 ; 4.5 ; 6.0$ and $7.5 \%$ ) with six replications. At the harvest point were evaluated the growth and production, nitrogen, phosphorus, potassium and sodium, as well as gas exchange plant with infrared gas meter (IRGA). The results showed that the fertilizer concentrations did not affect production, growth, levels of nutrients evaluated, and did not influence the gas exchange of plants.

Key words: Lactuca sativa; Microalgae; Nutrition; Gas exchange.

\footnotetext{
*Autor para correspondência

Recebido para publicação em 15/12/2016; aprovado em 20/02/2017

1 Engenheira agrônoma, mestre em Horticultura Tropical, Universidade Federal de Campina Grande (UFCG), Pombal-PB, Brasil. E-mail: debora_samara2008@hotmail.com

${ }^{2}$ Universidade Federal de Campina Grande, Graduando em Agronomia. Rua João Leite, 517, Pereiros, CEP 58840-000, Pombal-PB, Brasil. E-mail: jacksonnobrega@hotmail.com

${ }^{3}$ Universidade Federal de Campina Grande, Professora Doutora do Centro de Ciência e Tecnologia Agroalimentar. Rua João Leite, 517 , Pereiros, CEP 58840000, Pombal-PB, Brasil. E-mail: raileneherica@ ccta.ufcg.edu.br

${ }^{4}$ Universidade Federal de Campina Grande, Professor Doutor do Centro de Ciência e Tecnologia Agroalimentar. Rua João Leite, 517, Pereiros, CEP 58840000, Pombal-PB, Brasil. E-mail: jhosinal_araujo@yahoo.com.br

5 Engenheiro Agrônomo, Mestrando em Horticultura Tropical, Universidade Federal de Campina Grande (UFCG), Pombal, PB, Brasil. E-mail: wellinghton_guedes@hotmail.com

${ }^{6}$ Biotecnólogo, mestre em Ciências, doutor em Engenharia de Processos, Instituto Fazenda Tamanduá, Patos-PB, Brasil. E-mail: josefranciraldo@gmail.com
} 


\section{INTRODUÇÃO}

Dentre as hortaliças folhosas, a alface é uma das olerícolas economicamente mais importantes do mundo. De acordo com os dados da Organização das Nações Unidas para Agricultura e Alimentação, a produção mundial de alface e chicória em 2012 foi de 24,94 milhões de toneladas (FAO, 2015). No Brasil, em 2011, a produção de alface foi de 1,27 milhões de toneladas (REETZ et al., 2014), e destaca-se como maior consumidor da América do Sul (PINTO et al., 2010). Estima-se que sejam cultivados em torno de 35 mil hectares de alface anualmente no Brasil (LOPES et al., 2010).

Atualmente, o uso de microalgas na agricultura, especialmente como biofertilizante ou bioestimulante tem despertado o interesse de muitos produtores, com o intuito de melhorar o desempenho produtivo de plantas cultivadas (CHOJNACKA et al., 2012). As microalgas existem em um variado número de classes e são distinguidas, principalmente, pela sua pigmentação, ciclo de vida e estrutura celular, sendo que uma das principais espécies utilizadas comercialmente é a Spirulina platensis (SCHMITZ et al., 2012). Essa microalga apresenta na sua forma comercial, uma série de substâncias orgânicas e inorgânicas em elevada concentração que a caracteriza com um produto de elevado potencial para ser empregado como biofertilizante (PRIYADARSHANI; RATH, ,2012).

Devido ao potencial das microalgas para uso em sistemas de produção mais sustentáveis como a agricultura orgânica e a agricultura biodinâmica, uma série de trabalhos foram realizados com o objetivo de avaliar o efeito de fertilizantes à base de microalgas em algumas culturas (ZODAPE et al., 2011; PAUDEL et al., 2012; SHALABY; EL-RAMADY, 2014; TARRAF et al., 2015; GARCIAGONZALEZ; SOMMERFELD, 2015). Em muitos desses trabalhos observou-se efeito positivo desses produtos, quando aplicados principalmente via foliar, em culturas como pimenta (ALY; ESAWY, 2008), alho (SHALABY; ELRAMADY, 2014), arroz (PAUDEL et al., 2012) e tomate (ZODAPE et al., 2011).

Em estudo realizado por Ferrazza e Simonetti (2010), observou-se que algas marinhas (Ascophyllum nodosum) aplicadas via foliar na cultura da soja proporcionaram aumento no peso de grãos. A aplicação foliar desta microalga em pimenta, em condições de campo, no Egito, proporcionou produtividade semelhante à adubação padrão com NPK (ALY; ESAWY, 2008).

Trabalhos com fertilizante orgânico a base de Spirulina platensis são escassos, principalmente com hortaliças folhosas como a alface. Desta forma, o objetivo do presente estudo foi avaliar a produção, aspectos nutricionais e o efeito na fisiologia da alface em função de diferentes manejos de adubação foliar com fertilizante orgânico a base de Spirulina platensis.

\section{MATERIAL E MÉTODOS}

A pesquisa foi realizada na Universidade Federal de Campina Grande (UFCG), no Centro de Ciências e Tecnologia Agroalimentar (CCTA), Campus Pombal, Paraíba, no período de junho a julho de 2014. Segundo a classificação de Köppen, o clima predominante é o Aw' (quente e úmido com chuvas de verão-outono e precipitações pluviométricas anuais em torno de $800 \mathrm{~mm}$ ). A precipitação pluviométrica acumulada no período experimental foi de 41,4 $\mathrm{mm}$, determinada através do uso de um pluviômetro e registro diário da temperatura e umidade relativa do ar com termohigrômetro digital com cabo extensor - TH 439 (Figura 1).

Figura 1. Temperatura e umidade relativa do ar da área experimental, durante o período de crescimento da alface cv 'Elba'. Pombal. Paraíba.

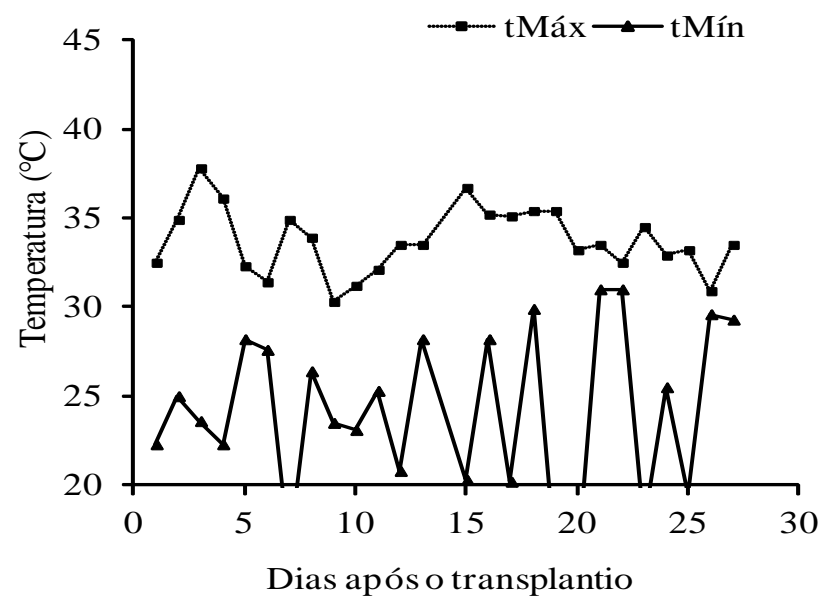

Fonte: Autor (2017)

Utilizou-se a cultivar de alface 'Elba', manejada conforme as recomendações de Maldonade et al. (2014). A produção das mudas de alface foi realizada em casa de vegetação, utilizando bandejas de poliestireno expandido constituídas por 288 compartimentos, preenchidas com substrato comercial (Baseplant $\left.{ }^{\circledR}\right)$. As bandejas foram dispostas sobre bancadas de madeira, onde foram semeadas na razão de três sementes por célula, efetuando-se desbaste

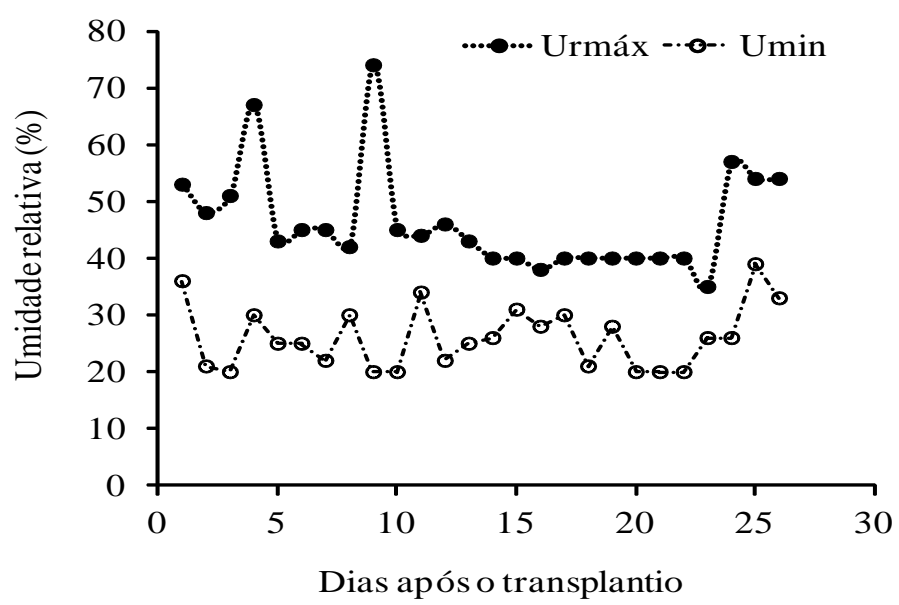

aos dez dias após o transplantio (DAT) e mantendo-se uma muda por compartimento.

O preparo do solo consistiu em uma aração e uma gradagem, na profundidade de $20 \mathrm{~cm}$ e, em seguida, foram construídos os canteiros. Nesta ocasião, foi coletada amostra de solo, na profundidade de 0 a $20 \mathrm{~cm}$ e encaminhada ao laboratório para as análises química e física (Tabela 1) conforme procedimentos descritos pela Embrapa (2011). O 
solo da área não recebeu qualquer adubação mineral, antes ou durante o desenvolvimento das plantas.

Os canteiros mediram 16,1 $\mathrm{m}$ de comprimento, 1,05 m de largura e altura de $20 \mathrm{~cm}$, sombreados com sombrite a $50 \%$, suspensos a altura de $1,20 \mathrm{~m}$ do solo. Cada canteiro separou-se seis parcelas, constituído de 32 plantas, no espaçamento de $0,25 \times 0,25 \mathrm{~m}$, sendo a área útil constituída de 12 plantas. O transplantio das mudas para o campo foi realizado quando as plantas apresentaram quatro folhas definitivas.

O sistema de irrigação utilizado foi por gotejamento, com frequência de quatro regas diárias e duração de 15 $\mathrm{min} /$ rega, reduzindo ou suspendendo a irrigação em dias de chuva. Periodicamente realizou capina manual com o intuito de eliminar o excesso de plantas daninhas em volta das plantas.

O experimento foi instalado no delineamento de blocos ao acaso (DBC), com seis tratamentos e seis blocos. Os tratamentos foram constituídos pelas concentrações $0 ; 1,5$; 3,$0 ; 4,5 ; 6,0$ e 7,5\% (m/v) do fertilizante orgânico a base de Spirulina platensis. Sendo a composição química e física do fertilizante (Tabela 2). As aplicações das doses do fertilizante via pulverização foliar, foram realizados a 1, 7, 14, 21 e 28 dias após o transplantio (DAT) das mudas para o campo, sempre no final da tarde, após irrigação das plantas, considerando-se o ponto de escorrimento do produto na planta, como referência ao volume da calda aplicado por planta.

Tabela 1. Análise química e física do solo utilizado para o cultivo de alface cv. 'Elba', antes do transplantio das mudas para o campo. UFCG, Pombal, Paraíba

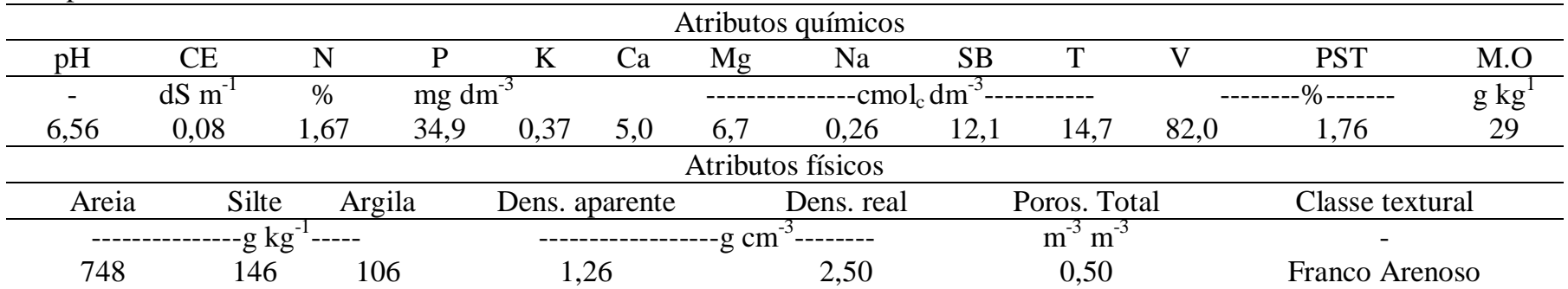

pH em água; SB: Soma de Bases Trocáveis; CEes: condutividade elétrica do extrato de saturação. V: Saturação por Bases; PST: Percentagem de Sódio Trocável.

Tabela 2. Constituição química e física do fertilizante orgânico a base de Spirulina platensis. UFCG, Pombal, Paraíba.

\begin{tabular}{|c|c|c|c|c|c|c|c|c|c|c|c|c|c|}
\hline $\mathrm{pH}$ & $\mathrm{CE}$ & $\mathrm{N}$ & $\mathrm{P}$ & K & $\mathrm{Ca}$ & $\mathrm{Mg}$ & $\mathrm{S}$ & $\mathrm{Na}$ & $\mathrm{CO}$ & \multicolumn{2}{|c|}{ M.O } & cinzas & umid. \\
\hline & $\mathrm{dS} \mathrm{m} \mathrm{m}^{-1}$ & & & & & & $\mathrm{~g} \mathrm{~kg}^{-}$ & & & \multirow{2}{*}{\multicolumn{2}{|c|}{947,0}} & & \\
\hline 3,7 & 1,04 & 44,0 & 8,2 & 6,8 & 1,6 & 2,3 & 4,5 & 2,0 & 259,5 & & & 5,30 & 764 \\
\hline $\mathrm{C} / \mathrm{N}$ & CTC & \multicolumn{2}{|c|}{$\mathrm{CTC} / \mathrm{CO}$} & \multicolumn{3}{|c|}{ Índice salino } & $\mathrm{Fe}$ & $\mathrm{Mn}$ & $\mathrm{Cu}$ & $\mathrm{Zn}$ & B & Co & \\
\hline & \multicolumn{3}{|c|}{$\mathrm{mol}_{\mathrm{c}} \mathrm{kg}^{-1}$} & & \multicolumn{2}{|c|}{$\%$} & & & $----m$ & (--.. & & & \\
\hline 5,0 & 130 & 5 & & 2,90 & & & 80,0 & 15,0 & 10,0 & 60 & 245,0 & 15,0 & \\
\hline
\end{tabular}

M.O: matéria orgânica; CO: carbono orgânico; CE: Condutividade elétrica.

Aos 38 DAT, foram determinadas as trocas gasosas das plantas, onde foi estimada a taxa de assimilação de $\mathrm{CO}_{2}(\mathrm{~A})$ transpiração $(E)$, condutância estomática $(\mathrm{gs})$ e concentração interna de $\mathrm{CO}_{2}(\mathrm{Ci})$. As avaliações foram realizadas em folhas completamente desenvolvidas do centro da planta, no período de 7:00 às 8:00 horas da manhã. De cada tratamento, selecionou-se uma planta, a qual se fez duas leituras, utilizado o analisador de gás no infravermelho (IRGA) LCpro (Analytical Development, Kings Lynn, UK) com fonte de luz constante de $1.200 \mu \mathrm{mol}$ de fótons $\mathrm{m}^{-2} \mathrm{~s}^{-1}$.

Aos 40 DAT as plantas da parcela útil foram colhidas e separadas em raízes e parte aérea. Na parte aérea foi obtido o diâmetro longitudinal (DLPA), diâmetro transversal (DTPA) e a matéria fresca (MFPA). As partes individualizadas foram secas em estufa a $60-65^{\circ} \mathrm{C}$ para obtenção da matéria seca da parte aérea (MSPA) e matéria seca de raízes (MSR). O material vegetal seco passou pelo processo de moagem, em moinho tipo Willey para a determinação dos teores de N, P, K e Na (MALAVOLTA et al., 1997).

Os dados foram submetidos à análise de variância e de regressão polinomial ao nível de $5 \%$ de significância, utilizando-se o programa SISVAR $®$ (FERREIRA, 2011).

\section{RESULTADOS E DISCUSSÃO}

As doses do fertilizante orgânico não afetaram significativamente nenhuma das variáveis avaliadas na cultura da alface conforme a análise de variância. Da mesma forma, pela análise de regressão, não houve ajuste destas variáveis em função das doses do produto testado. Diferentemente do observado em outros trabalhos com outras espécies (ALY; ESAWY, 2008; MÓGOR et al., 2008; ZODAPE et al., 2011).

Apesar de não haver diferença entre os tratamentos, o crescimento das plantas, medido pelos valores matéria fresca da parte aérea (Figura 2A), diâmetro longitudinal (Figura 2E) e transversal da parte aérea (Figura $2 \mathrm{~F}$ ) foram semelhantes ao obtido por Porto et al. (2014) para a cv. Elba.

Apesar do considerável teor de $\mathrm{N}$ no fertilizante orgânico (Tabela 2), o produto não alterou os teores deste nutriente na alface. Observou-se que para o N (Figura 3A), os teores encontrados neste trabalho corroboram com os obtidos por Oliveira et al. (2010) e Resende et al. (2012). Embora não tenha sido realizada a adubação mineral, os valores encontrados estão próximos da faixa considerada adequada para a cultura que é de 30 a $50 \mathrm{~g} \mathrm{~kg}^{-1}$ de N (VAN RAIJ et al., 1997). Da mesma forma, os teores fósforo (Figura 3B) obtidos na parte aérea estão dentro da faixa (4 a $6 \mathrm{~g} \mathrm{~kg}^{-1}$ ) considerada como adequada para a cultura (REUTER; ROBINSON, 1997). Desta forma, embora o fertilizante 
orgânico não tenha contribuído com a nutrição fosfatada da cultura, as concentrações do solo (Tabela 1) garantiu o adequado suprimento deste nutriente à cultura.

Os teores de K (Figura 3C) situaram-se entre 20 e $23 \mathrm{~g}$ $\mathrm{kg}^{-1}$, diferindo dos obtidos por Bernardi et al. (2005), que obtiveram em alface cv. Regina, teores de K variando de 32,3 a $37,2 \mathrm{~g} \mathrm{~kg}^{-1}$. Os teores de $\mathrm{K}$, observados neste trabalho, estão abaixo do preconizado para a cultura (TRANI; RAIJ, 1997). Conforme Boaretto et al. (2009), a exigência da alface pelo potássio é superior ao do nitrogênio, fato possivelmente relacionado com sua exigência em água, pois o K é requerido, para manter o controle hídrico das plantas (TAIZ; ZEIGER,
2004). Assim, as quantidades de potássio veiculadas nas concentrações do fertilizante orgânico (Tabela 2) não contribuíram para incrementar os teores desse nutriente na parte aérea da cultura, onde os valores variaram de 20,09 a 22,74 dag kg-1 (Figura 3C). É importante salientar que os teores de $\mathrm{K}$ no solo (Tabela 1) da área experimental são considerados altos e, portanto, não deve ter sido limitante à produção adequada da cultura. Além disso, os teores de um nutriente variam em função do clima, manejo do solo e do tipo de cultivar, o que pode justificar as diferenças mencionadas para o potássio.

Figura 2. Matéria fresca da parte aérea (MFPA) (A), matéria seca da parte aérea (MSPA) (B), matéria seca de raízes (MSR) (C), matéria seca total (MST) (D), diâmetro longitudinal (DLPA) (E) e transversal (DTPA) (F) da parte aérea da alface cv. Elba, em função das concentrações do fertilizante orgânico a base de Spirulina platensis.
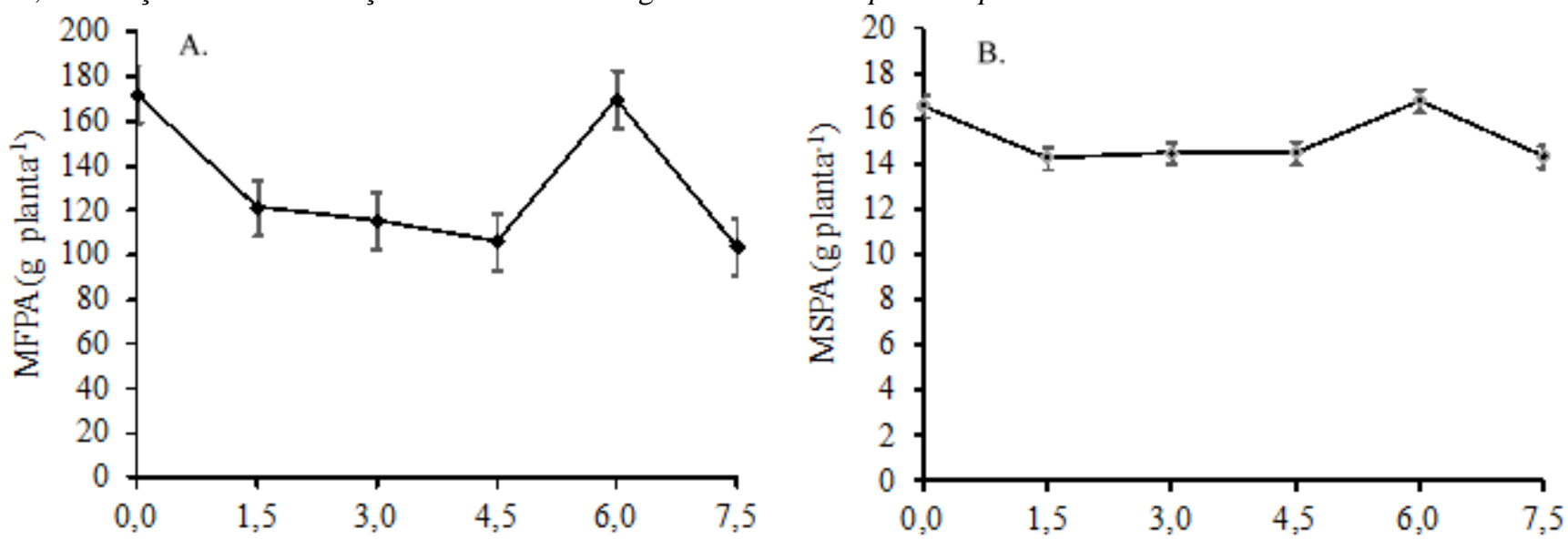

Concentrações de Spirulina platensis (\%)

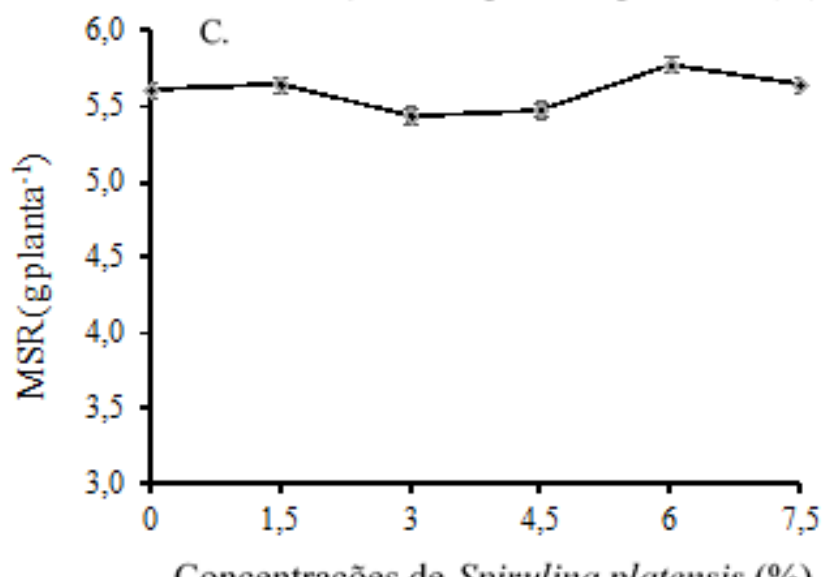

Concentrações de Spirulina platensis (\%)
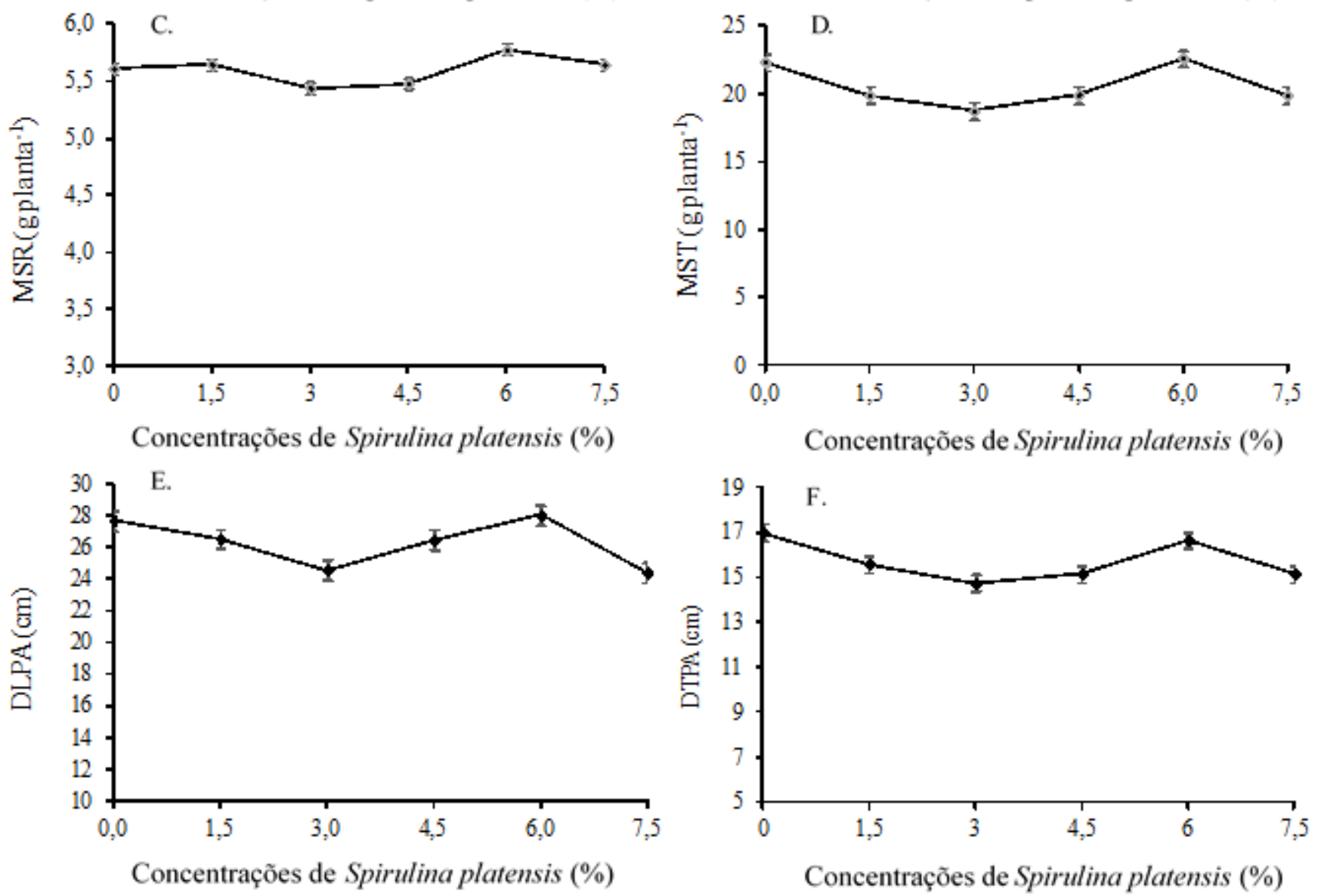
Figura 3. Teores de nitrogênio (A), fósforo (B), potássio (C) e sódio (D) da parte aérea da alface cv. Elba, em função das concentrações do fertilizante orgânico a base de Spirulina platensis.
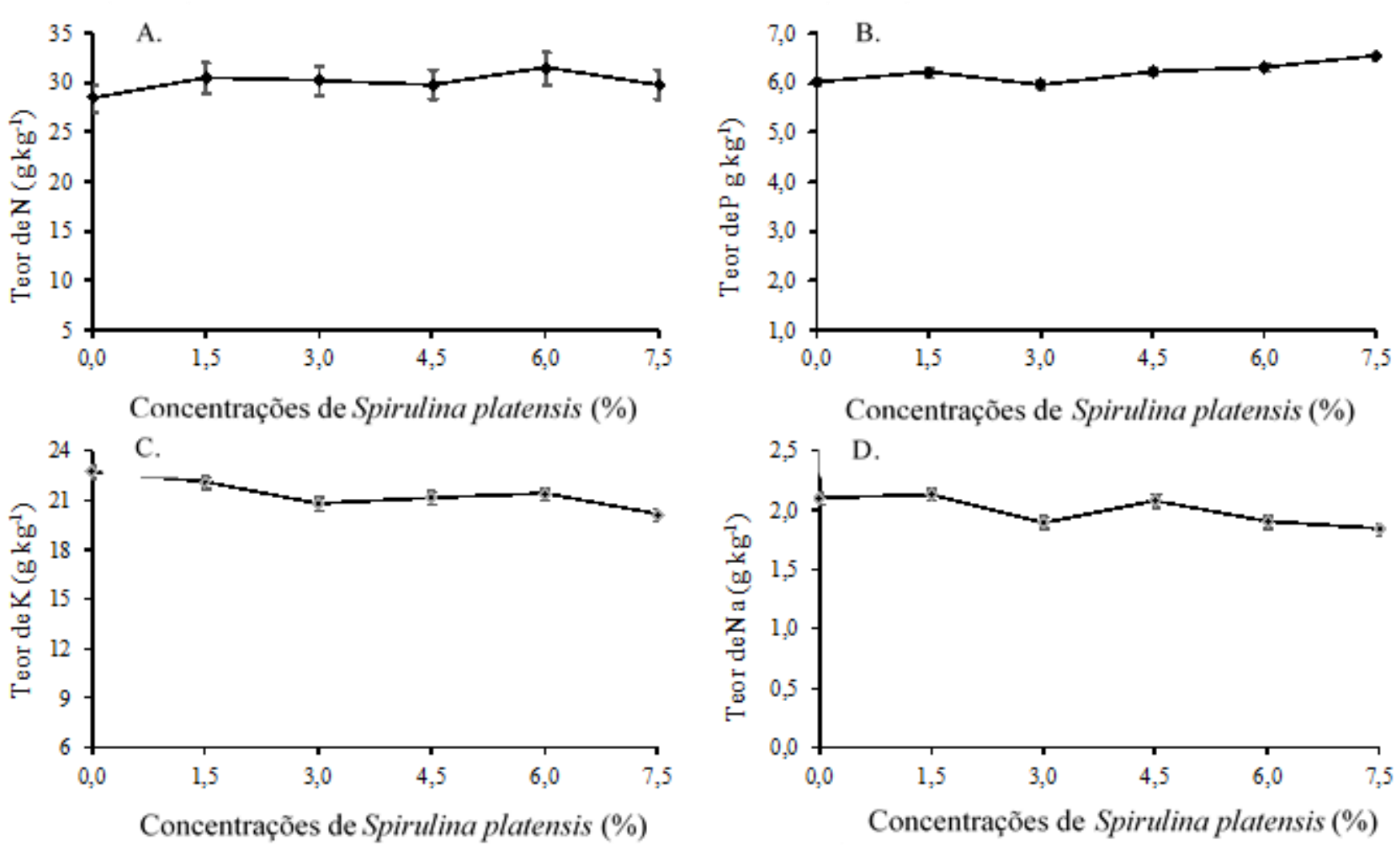

Como verificou-se para as demais variáveis, as doses do fertilizante orgânico não afetaram os valores de concentração intercelular de $\mathrm{CO}_{2}$ (Figura 4A), taxa de transpiração (Figura 4B), condutância estomática (Figura 5A) e taxa fotossintética (Figura 5B). Estas variáveis são úteis para diagnosticar alterações fisiológicas nas plantas quando submetidas às diversas condições ambientais como as variações na disponibilidade de nutrientes (SILVA et al., 2012). Os valores observados neste trabalho, para estas variáveis, são inferiores, mas compatíveis com os obtidos por Silva et al. (2012) em quatro cultivares de alface. Além do cultivar, diferentes diferenças nos valores para trocas gasosas podem ocorrer principalmente quando as medidas são tomadas sob diferentes condições climáticas.

A concentração intercelular de $\mathrm{CO}_{2}$ (Figura 4A), embora não tenha sido afetada pelas doses do produto testado, apresentou comportamento praticamente inverso ao obtido para a taxa fotossintética (Figura 4D). Este efeito é resultante do consumo interno de $\mathrm{CO}_{2}$ da célula, durante o processo fotossintético (TAIZ; ZEIGER, 2004), embora não tenha sido observado similaridade da taxa fotossintética com a abertura estomática (Figura 5B) e a taxa de transpiração (Figura 4B).

$\mathrm{O}$ fato de não ter observado efeito do fertilizante sobre a produção, nutrição ou fisiologia da alface cv. 'Elba' pode ter várias explicações. Como não houve limitação ao desenvolvimento da cultura, em relação aos fatores edafoclimáticos, provavelmente a cultura tenha expressado seu máximo potencial produtivo, sem necessitar de qualquer fertilizante ou estimulante adicional. Além disso, como a calda com o fertilizante preparado para a aplicação não, se tratar de uma solução verdadeira, é possível que a quantidade efetivamente absorvida pela planta, não tenha sido suficiente para promover os efeitos esperados. Assim, trabalhos de

pesquisas com este tema, mais aprofundados em relação à forma de preparo ou de aplicação do produto, devem ser explorados no futuro, principalmente com culturas nutricionalmente mais exigentes.

Figura 4. Concentração intercelular de $\mathrm{CO}_{2}$ (A) e transpiração (D) da alface cv. Elba, em função das concentrações do fertilizante orgânico a base de Spirulina platensis.
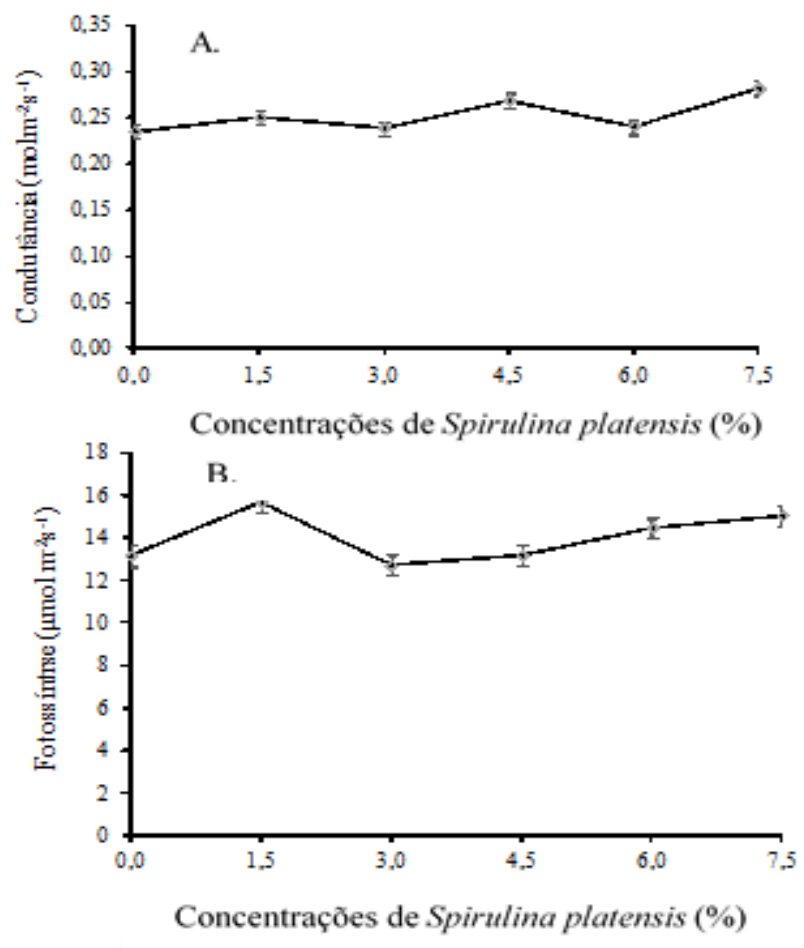
Figura 5. Condutância estomática (A) e taxa fotossintética (B) da alface cv. Elba, em função das concentrações do fertilizante orgânico a base de Spirulina platensis.
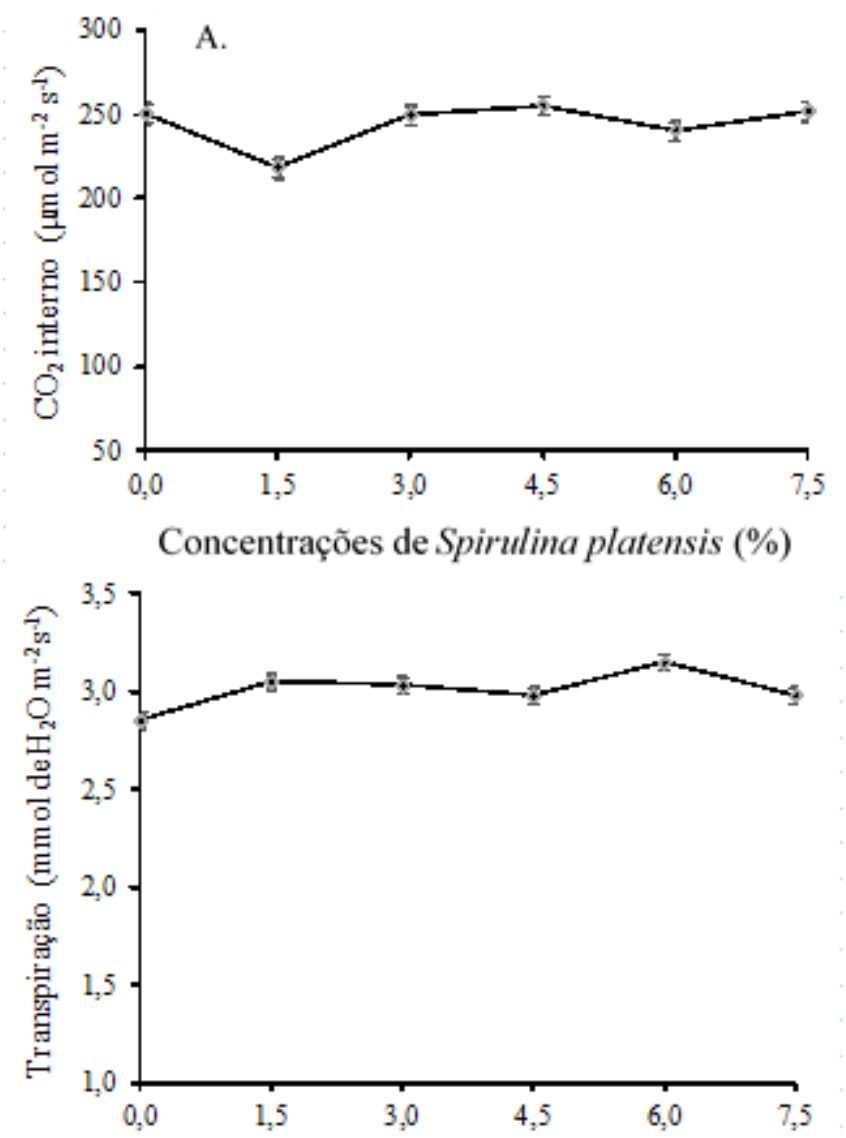

Concentrações de Spirulina platensis (\%)

\section{CONCLUSÕES}

O fertilizante orgânico a base de Spirulina platensis aplicado via foliar na alface 'Elba', sob as condições em que foi cultivada, não influencia seu crescimento, produção, teores foliares de $\mathrm{N}, \mathrm{P}, \mathrm{K}$ e $\mathrm{Na}$, nem altera seu estado fisiológico em termos de trocas gasosas.

\section{REFERÊNCIAS}

ALY, M. S.; ESAW, M. A. Evaluation of Spirulina Platensis as Bio Stimulator for Organic Farming Systems. Journal of Genetic Engineering and Biotechnology, v. 6, n. 1, p. 1-7, 2008.

BERNARDI, A. C. C.; VERRUMA-BERNARDI, M. R.; WERNECK, C. G.; HAIM, P. G; MONTE, M. B. M. Produção, aparência e teores de nitrogênio, fósforo e potássio em alface cultivada em substrato com zeólita. Horticultura Brasileira, v. 23, n. 4, p. 920-924, 2005.

BOARETTO, A. E.; RIAJ, B. V.; SILVA, F. C.; ChITOLINA, J. C.; TEDESCO, M. J.; CARMO, C. A. F. S. Amostragem, acondicionamento e preparação das amostras de plantas para análise química. In: SILVA, F. C. (Eds.). Manual de análises químicas de solos, plantas e fertilizantes. Brasília: Embrapa /MAPA, 2009. p. 59.
CHOJNACKA, K.; SAEID, A.; MICHALAK, I. The possibilities of the application of algal biomass in the agriculture. Chemik, v. 66, n. 11, p. 1235-1248, 2012.

EMBRAPA. Empresa Brasileira de Pesquisa Agropecuária. Manual de métodos de análises de solos. 2ed. Rio de Janeiro: Embrapa Solos, 2011. 230 p.

FAOSTAT. 2015. Production. Disponível em http://faostat.fao.org. Acessado em 18 de abril 2015.

FERRAZZA, D.; SIMONETTI, A. P. M. M. Uso de extrato de algas no tratamento de semente e aplicação foliar, na cultura da soja. Cultivando o Saber, v. 3, n. 2, p. 48-57, 2010.

FERREIRA, D. F. Sisvar: a computer statistical analysis system. Ciência e Agrotecnologia, v. 35, n. 6, p. 1039-1042, 2011.

GARCIA-GONZALEZ, J.; SOMMERFELD, M. Biofertilizer and biostimulant properties of the microalga Acutodesmus dimorphus. Journal Applied Phycology, v. 28, n. 2, p. 10511061, 2015.

LOPES, C. A.; QUEZADO-DUVAL, A. M.; REIS, A. Doenças da alface. Embrapa Hortaliças: Brasília, 2010. 68 p.

MALAVOLTA, E.; VITTI, G. C.; OLIVEIRA, S. A. Avaliação do estado nutricional de plantas: princípios e aplicações. Piracicaba: Potafos, 1997. 319 p.

MALDONADE, I. R.; MATTOS, L. M.; MORETTI, C. L. Manual de boas práticas na produção de Alface. Brasília: Embrapa Hortaliças, 2014. 44 p.

MÓGOR, A. F.; ONO, E. O.; RODRIGUES, J. D.; MÓGOR, G. Aplicação foliar de extrato de alga, ácido L-glutâmico e cálcio em feijoeiro. Scientia agraria, v. 9, n. 4, p. 431-437, 2008.

OLIVEIRA, N. L. C.; PUIATTI, M.; SANTOS, R. H. S.; CECON, P. R.; BHERING, A. S. Efeito da urina de vaca no estado nutricional da alface. Revista Ceres, Viçosa, v. 57, n. 4, p. 506-515, 2010.

PAUDEL, Y. P.; PRADHAN, S.; PANT, B.; AND PRASAD, B. N. Role of blue green algae in rice productivity. Agriculture and Biology Journal of North America, v. 3, n. 8, p. 332-335, 2012.

PINTO, P.A.C. SANTOS, N.G.N.; GERMINO, G.F.S.; DEON, T.D.; SILVA, A.J. Eficiência agronômica de extrato de algas Ascophyllum nodosum (Natural WSP) aplicado na cultura da alface (Lactuca sativa L.). In: CONGRESSO DA SOCIEDADE BRASILEIRA DE CIÊNCIA DO SOLO (SBCS), 30, Recife, 2005, Anais. Recife, Sociedade Brasileira de Ciência do Solo, 2005. CD-ROM.

PORTO, V. C. N.; FERREIRA, L. L.; SANTOS, E. C. S.; ALMEIDA, A. E. S.; BEZERRA, A. F. M. S.; OLIVEIRA, F. S. 2014. Comportamento de cultivares de alface no Oeste Potiguar. Revista de Ciências Agrárias, v. 57, n. 1, p. 9-14, 2014. 
PRIYADARSHANI, I.; RATH, B. Commercial and industrial applications of micro algae - A review. Journal of Algal Biomass Utln, v. 3, n. 4, p. 89-100, 2012.

REETZ, E. R.; KIST, B. B.; SANTOS, C. E.; CARVALHO, C.; DRUM, M. Anuário brasileiro de hortaliças. Gazeta Santa Cruz, 2014. 88 p.

RESENDE, G. M.; ALVARENGA, M. A. R.; YURI, J. E.; SOUZA, R. J. Rendimento e teores de macronutrientes em alface americana em função de doses de nitrogênio e molibdênio. Horticultura Brasileira, v. 30, n. 3, p. 373-378, 2012.

REUTER, D. J.; ROBINSON, J. B. Plant analysis: an interpretation manual. Sydney: Inkata Press, 1997. 572 p.

SCHMITZ, R.; MAGRO, C.; COLLA, L. M. Aplicações ambientais de microalgas. Revista Ciências Exatas Aplicadas e Tecnológicas, v. 4, n. 1, p. 48-60, 2012.

SHALABY, T. A.; EL-RAMADY, H. Effect of foliar application of bio-stimulants on growth, yield, components, and storability of garlic (Allium sativum L.). Australiam Journal of Crop Science, v. 8, n. 2, p. 271-275, 2014.

SILVA, M. B.; ECHER, M. M.; MATTIELLO, V. D.; KLOSOWSKI, E. S.; RODRIGUES, L. F. O. S.; PINTO JUNIOR, A. S.; GUIMARÃES, V. F. Trocas gasosas em cultivares de alface americana sob cultivo protegido, com e sem tela termo-refletora, em sistema orgânico. Horticultura Brasileira, v. 30, n. 2, p. 1588-1595, 2012.

TAIZ, L.; ZEIGER, E. Fisiologia vegetal. Porto Alegre: Artmed, 2013. 918 p.

TARRAF, S. A.; TALAAT, I. M.; EL-SAYED, AE-K. B.; BALBAA, L. K. Influence of foliar application of algae extract and amino acids mixture on fenugreek plants in sandy and clay soils. Nusantara Bioscience, v. 7, n. 1, p. 33-37, 2015.

TRANI, P. E.; RAIJ, B. Hortaliças. In: RAIJ B; CANTARELLA H.; QUAGGIO, J. A.; FURLANI, A. M. C. Recomendações de adubação e calagem para o Estado de São Paulo. Campinas: IAC. 1997. p. 157-163.

VAN RAIJ, B.; CANTARELLA, H.; QUAGGIO, J. A.; FURLANI, A. M. C. Recomendações de adubação e calagem para o Estado de São Paulo. 2 ed. Campinas: IAC, 1997. 285 p. (Boletim técnico, 100).

ZODAPE, S. T.; GUPTA, A.; BHANDAR, I. S. C.; RAWAT, U. S.; CHAUNHARY, D. R.; ESWARAN, K.; CHIKARA, J. Foliar application of seaweed sap as biostimulant for enhacement of yield and quality of tomato (Lycopersicon esculentum Mill.). Journal of Scientific and Industrial Research, v. 70, p. 215-219, 2011. 